\title{
Las Causas Estructurales de la Pluralidad Legal en el Perú
}

ARMANDO GUEVARA GIL *

Miembro del Instituto Rivagüero, profesor en la Facultad de Derecho de la Pontificia Universidad católica del Perú

en una concepción maniquea sobre realidades sociolegales más bien dinámicas, fluidas e interactivas. Esta visión reduccionista se estrecha aún más cuando se asume que la única causa de la pluralidad legal es la diversidad cultural peruana.

Primero, el marcado positivismo jurídico imperante en las facultades de derecho y en los operadores legales. La ecuación Derecho = Estado satura el panorama de los hombres de Derecho y equivocadamente atribuye el monopolio normativo y jurisdiccional al Estado peruano. Segundo, el desinterés de los antropólogos profesionales -el establishment nacional- en la materia. El pluralismo jurídico no ha concitado su atención etnográfica o teórica porque las ciencias sociales peruanas también son tributarias de ese mito que asigna un carácter exclusivamente estatal a las normatividad socialmente vigente.

En los últimos años, el tratamiento de la pluralidad legal ha sido tímido y tedioso pues se siguen manejando marcos teóricos funcionalistas y estructural-funcionalistas que limitan severamente la comprensión de un fenómeno tan complejo y dinámico (ver Guevara y Thome 1992/1999). En la mayor parte de los trabajos se confunde pluralismo con dualismo social, cultural o legal; desembocando
Además de superar esa imagen dicotómica y reducida de la realidad socio-legal, sería recomendable dar un paso más, "descentrando" el tratamiento y el debate sobre la pluralidad jurídica. Hay una fijación tradicional en temas de Derecho Penal (delitos) por ser los más llamativos, apremiantes y ejemplificadores de los dilemas implícitos en la diversidad cultural y legal. Sin embargo, la cuestión del pluralismo jurídico en el campo del Derecho "Civil" (contratos, propiedad, posesión, parentesco) es tanto o más importante en la vida cotidiana y por eso debería ser incorporada en la agenda de investigación (e.g., De Soto 1986; Revilla y Price 1992). Estudiar al Derecho más allá de su función represiva y punitiva es fundamental para explorar temas capitales en la estructuración de las sociedades locales (e.g., indígenas, campesinas, urbano-marginales). 
En este trabajo damos un paso atrás, preguntándonos por las causas eficientes que producen la pluralidad legal en el Perú. Consideramos que la cuestión es pertinente porque la configuración y articulación de la pluralidad no responde a un esquema predeterminado sino a las causas específicas que la originan. Es indudable que la identificación y el análisis de éstas exigen la realización de trabajos de campo puntuales $\mathrm{y}$ minuciosos. Además, se requerirá elaborar una teoría de alcance general que articule las explicaciones parciales o de rango medio que se irán formulando para comprender la dinámica sociolegal propia de contextos plurales. Ambas tareas están pendientes debido al limitado desarrollo de la antropología legal peruana (ver Guevara Gil 1998), pero es necesario intentar esa exploración aunque sea en forma panorámica y limitada. Por eso, a manera de avance, proponemos esta aproximación inicial a las causas estructurales que generan nuestra diversidad legal.

Otro objetivo de esta contribución es presentar los factores que a nuestro juicio cuestionan la vigencia plena del Derecho oficial y fomentan la emergencia o subsistencia de espacios sociales y normativos que compiten e interactúan con la legalidad estatal. Es más, las condiciones sociales y económicas que el sistema legal oficial enfrenta son de tal magnitud que resulta sociológicamente imposible sostener que el Estado ha logrado afirmar su hegemonia legal sobre todo el territorio nacional y sus múltiples paisajes humanos. La dialéctica entre esos espacios sociales y las prescripciones estatales produce, precisamente, las situaciones de pluralidad que necesitamos explorar con más detenimiento para elaborar un verdadero mapa etnográfico y etnológico de la realidad legal peruana. Como hemos indicado, en esta tarea será imprescindible cuestionar y superar la visión reduccionista que limita las causas de la pluralidad jurídica a la diversidad cultural (pluralidad legal = multiculturalidad). Será necesario, más bien, comprender cómo otras dimensiones sociales, políticas y económicas contribuyen a la formación e interacción de los universos normativos involucrados.

Estos apuntes se basan en las dos conferencias dictadas en Iquitos el 19 de febrero de 1999 en el I Seminario-Taller de Pluralismo Legal y Ordenamiento Normativo. El evento, dirigido a vocales, jueces, fiscales y operadores jurídicos en general, fue organizado por la Corte Superior de Justica de Loreto, la Facultad de Derecho de la Universidad Nacional de la Amazonía y el Servicio Holandẹ́s de Cooperación al Desarrollo-Programa Amazonia (SNV-Iquitos). Fue muy interesante participar en un seminario de esta naturaleza, tanto por su ariginalidad temática como por el esfuerzo organizativo que significó. El trabajo realizado por los organizadores del Seminario-Taller se encuentra ampliamente justificado y ojalá se replique. Ellos tienen mucho que decir y hacer sobre un tema tan relevante para las sociedades amazónicas. Además, es plausible que esta iniciativa se haya originado en Iquitos porque tanto las universidades como las ONGs limeñas, que supuestamente lideran la agenda intelectual nacional, ni siquiera ventilan un tema de esta naturaleza o lo hacen esporádicamente. 
Agradezco al equipo de SNV-Iquitos en las personas de Hans Heijdra, Rafael Meza Castro, Gabriel García Villacrez y Miguel Donayre Pinedo; y a los doctores Wilber Villafuerte Mogollón y Aldo Atarama Lonzoy, de la Corte Superior de Iquitos por su iniciativa y hospitalidad. También agradezco a Gabriel y a Patricia Urteaga Crovetto por haber transcrito mis intervenciones en el seminario-taller. Patricia, Armando Zapata Román y Martín Carrillo Calle plantearon sugerentes críticas a la versión inicial de este texto y ojalá que haya podido subsanarlas.

Cabe advertir que el trabajo carece del usual aparato crítico por tratarse de un texto introductorio. Sólo remitimos a una bibliografía básica incluida al final del texto.

\section{Causas estructurales de la pluralidad legal en el Perú}

El pluralismo jurídico consiste en la coexistencia e interacción de diferentes ordenamientos normativos sobre las mismas situaciones sociales en un espacio geo-político determinado (e.g., Estado-nación, imperio, confederación). Basados en esta realidad, los teóricos de la pluralidad legal plantean una premisa central, a saber: que el Derecho no es un monopolio del Estado. Por eso afirman que en oposición a las teorías monistas sobre la vigencia de un solo sistema legal en un espacio y tiempo determinado, lo que ocurre es que diversos "Derechos" tienen vigencia social en forma simultánea y conflictiva. En rigor, esta pluralidad es una cualidad estructural de cualquier sociedad porque ninguna está completamente subordinada a una sola fuente productora de derecho.

Más allá de las ideologías fundacionales y legitimadoras que desarrollan las organizaciones geo-políticas (e.g., estado-nación) para subordinar a otras entidades políticas (e.g., grupos étnicos), ninguna es capaz de regir y dominar por completo todo su escenario social y político. Al contrario, en su interior conviven múltiples formas sociales de actividad y afiliación que generan o pretenden generar sus propias legalidades más allá de los dictados oficiales. Ejemplos de estas esferas sociales pueden ser los grupos étnicos, las comunidades religiosas, las universidades, las fuerzas armadas, las asociaciones profesionales o gremiales, las ONGs, las corporaciones transnacionales, las comunidades campesinas $o$ nativas, y los núcleos urbanos informales.

Lo interesante es advertir que la pluralidad adquiere distintos rasgos y dimensiones en función de las peculiaridades de cada formación históricosocial. La legalidad estatal, plural en sí misma por los comandos divergentes que emite sobre los mismos hechos sociales (e.g., normas civiles y laborales sobre las relaciones de trabajo) colisiona con los derechos de esas esferas sociales y produce nuevas configuraciones regulatorias. Además, los propios agentes sociales involucrados redefinen $y$ rearticulan los elementos del derecho estatal en función de sus intereses. Al hacerlo reinventan constantemente su derecho local o consuetudinario y delinean sus márgenes de semi-autonomía (e.g., derechos posesorios en asentamientos urbano 
marginales; v er Revilla y Price 1992; De Soto 1986).

Bajo esta perspectiva y más allá de la mitología sobre el Estado y la nación, es indudable que el Perú es un país atravesado por enormes fracturas económicas, sociales y culturales. Estas quiebran cualquier espejismo sobre la supuesta homogeneidad nacional y la vigencia plena del Derecho estatal moderno. Para comprender esta realidad legal fracturada, es importante identificar las causas estructurales de la diversidad legal peruana.

En primer lugar, es necesario reconocer que diferenciación y exclusión tanto social como política. Ello potencia la diversidad normativa pues cada vez más sectores regulan sus relaciones sociales más allá de la legalidad estatal y de sus frágiles instituciones.

En segundo lugar, es preciso tomar en cuenta cuál es la actitud oficial frente a la compleja diversidad social. La respuesta estatal no puede ser más grandilocuente y equivocada. En vez de procesar y nutrirse de esa diversidad para proponer nuevas avenidas de regulación social, el estado sigue postulando y afirmando la vigencia de un "Derecho Moderno" autónomo, racional formal, sistemático y general, fundado en premisas que no se verifican en la promesa de la revolución independentista criolla no ha podido concretarse. El liberalismo decimonónico planteaba la necesidad histórica de crear un estadonación social, económica y culturalmente homogéneo y la vida cotidiana (e.g., que todos conocen la ley vigente, que la ley positiva es la principal fuente de derecho, que el propio estado respeta la pirámide normativa, que el sistema jurídico brinda seguridad y articulado. Pero ese mito fundante no se ha realizado ni se realizará porque somos un país heterogéneo, desarticulado $\mathrm{y}$ diferenciado pese a las políticas integracionistas, asimilacionistas o francamente etnocidas y hasta genocidas que se han desarrollado a lo largo de nuestra historia republicana. Además, los afanes de imponer "la modernidad" han colisionado con sustratos culturales y sociales que procesaron esas políticas en función de su propia consistencia $y$, de ese modo, han dado a luz nuevas realidades aún más heterodoxas e impredecibles desde el punto de vista de las políticas modernizadoras. En forma concurrente, la economía política del capitalismo peruano genera previsibilidad, que la ley es de aplicación universal y uniforme). Eso lo lleva a acelerar su producción legislativa y a diseñar instituciones incapaces de entrar en diálogo con la sociedad civil que afirma ámbitos normativos diferenciados del derecho oficial.

Aun considerando algunos limitados esfuerzos de flexibilidad intra-sistémica como los márgenes de autonomía reconocidos a las comunidades campesinas y nativas o la facultad asignada a las convenciones colectivas de trabajo para producir normas vinculantes entre las partes, la 
vocación del derecho estatal es eminentemente centralista. Los tímidos reconocimientos del derecho consuetudinario expresados, por ejemplo, en el artículo 149 de la actual constitución sobre la jurisdicción restringida y subordinada de las autoridades comunales (campesinas y nativas) o en el D.L. 22175 sobre la potestad de las autoridades comunales nativas para resolver controversias civiles de mínima cuantía y sancionar faltas de sus propios miembros, no son sino excepciones al discurso jurídico oficial que se sigue aferrando al ideal de crear un mundo regulado y regulable por un solo agente productor de normas: el estado. El resultado es una maraña normativa que deteriora la propia hegemonía legal estatal y produce la expansión o subsistencia de las legalidades que operan en las esferas sociales semi-autónomas.

En tercer lugar, es imprescindible situar al derecho estatal frente a la realidad social que pretende regular. Para ello referimos una serie de factores que invitan a reflexionar sobre la complejidad social, geográfica y cultural que enfrenta el estado al pretender afirmar la vigencia monopólica de su sistema legal. El primero de ellos es la propia geografía nacional. El Perú tiene $12285,000 \mathrm{~km} 2$ (ésta y todas las cifras son aproximadas). Comparándolo con países europeos que siempre inspiran a nuestros legisladores, es 5 veces más grande que Gran Bretaña, 3.5 veces más que Alemania, 4.3 veces más que Italia, 2.5 veces más que España y 2.3 veces más grande que Francia. En consecuencia, el reto espacial es mucho mayor y se incrementa con la verticalidad y extraordinaria diversidad de nuestra realidad geográfica. Basta señalar que el Perú es uno de los 10 países megadiversos del planeta pues tiene 84 de las 104 zonas de vida, 28 de los 32 climas existentes y varios records mundiales en variedad y abundancia de flora y fauna. Cualquier intento de manejar esta compleja realidad ecológica con normas de pretendida aplicación universal resulta, sencillamente, ilusorio. El segundo factor es la distribución de la población, cercana a los 25 millones. Si bien es cierto que la mayoría (2/3) vive en las ciudades y sólo un tercio en el campo, es importante tener en cuenta que las ciudades han crecido en forma explosiva y caótica, generando espacios urbanos y semi-urbanos en los que la presencia estatal es, a lo sumo, intermitente y fragmentaria (e.g., asistencialista, represiva o exactiva como las levas). El tercero es la diversidad de paisajes humanos.

Sólo para mencionar los tres que han sido más estudiados por la antropología legal peruana, señalemos que los pueblos jóvenes o asentamientos humanos urbano marginales en las ciudades peruanas albergan a unos 7 millones de personas. Sólo en Lima, por ejemplo, el $80 \%$ de la población vive en pueblos jóvenes, tugurios, urbanizaciones populares y asentamientos periféricos. En el área rural tenemos unas 4,500 comunidades campesinas, particularmente serranas, que cuentan con más de 3 millones de comuneros y que controlan el $15 \%$ de todo el territorio nacional. La Amazonia, por su parte, cubre el $60 \%$ del territorio y se estima que la población "indígena" supera las 250,000 personas (aproximadamente el 1\% de nuestra población). Allí viven unos 65 grupos étnicos que pertenecen a 14 familias lingüísticas y que hasta ahora han 
constituido unas 1,300 comunidades nativas. Así, una realidad geográfica tan disímil concurre con las diversas formas de organización social mencionadas y los universos simbólicos emergentes para producir un vasto mosaico humano.

Sin embargo, éstos no son los únicos factores que conspiran contra la vigencia universal, homogénea y obligatoria del derecho oficial. Las enormes brechas sociales y económicas también contribuyen a cuestionar esas premisas pues generan tal grado de disparidades que éstas devienen en insalvables y colocan a los agentes jurídicos en situaciones de exclusión o desventaja extrema. ¿Podemos afirmar, por ejemplo, que los 25 millones de peruanos somos realmente ciudadanos; que estamos en plena capacidad de ejercer nuestros derechos y obligaciones; que contamos con los suficientes recursos materiales y simbólicos para operar en el ámbito del derecho oficial? Sería iluso o cínico responder afirmativamente.

Breves referencias sobre la pobreza, el desempleo y la distribución del ingreso nacional nos ayudarán a retratar las dramáticas brechas que corroen nuestro tejido social. La primera, definida según el método de la línea de pobreza o el de las carencias críticas, afecta a la mitad de los peruanos. Sólo en Lima, el $80 \%$ de la población (más de 5 millones y medio de personas) se encuentra en situación de pobreza y el $90 \%$ de limeños destina el $80 \%$ de sus ingresos para solventar sus gastos de alimentación. Peor aún, cerca del $20 \%$ de peruanos padece extrema pobreza (recientes mediciones reducen el estimado al $15 \%$ pero debido al notorio manejo político de las estadísticas que practicaba el gobierno de Fujimori y al empeoramiento de la crisis económica anotamos el cálculo anterior). De estos 5 millones, más de $1 / 3$ corresponde a la población llamada "indígena", más de la mitad es mujer (por eso se habla de la feminización de la pobreza) y por lo menos el $50 \%$ de los niños padece desnutrición crónica. (EI Instituto Cuánto y el INEI definen a un pobre extremo como aquél que no puede gastar ni siquiera 3.5 nuevos soles al día en una canasta básica de alimentos. En cambio, un pobre es aquél que puede subvenir sus necesidades alimentarias mínimas pero no puede cubrir el costo de otros bienes y servicios esenciales como vivienda, educación, transporte o electricidad. En cualquier caso, su gasto diario no alcanza los 7 nuevos soles).

En términos de educación formal, los pobres extremos se encuentran en clara desventaja. Sólo 1 de cada 5 ha asistido a la escuela, el $60 \%$ cursó un solo grado de primaria y sólo el $20 \%$ tiene estudios secundarios. Si bien es cierto que se han hecho avances significativos en el número de personas alfabetas (87\% de la población en 1993 según los optimistas cálculos oficiales), la calidad de la educación escolarizada y el analfabetismo funcional obstaculizan el pleno goce de las habilidades adquiridas y, en consecuencia, de los derechos ciudadanos. El analfabetismo afecta a más de un millón y medio de personas, de los cuales el $70 \%$ son mujeres y el $62 \%$ vive en el campo, a la par que la deserción escolar es un fenómeno cada vez más cotidiano (casi $30 \%$ en niños de 13 a 17 años). 
Además, y esa es una constante en la historia del Perú, la pobreza rural es más aguda que la urbana. Así, mientras el $40 \%$ de los habitantes de la ciudad de Lima es pobre, esta situación afecta al $68 \%$ de la población de la sierra rural y al $70 \%$ de los pobladores de la selva rural. La asociación entre pobreza y pertenencia etnolingüística también es marcada. De las 4 millones y medio de personas que tienen como lengua materna el quechua, el aymara o una de las lenguas amazónicas, más de $1 / 3$ vive en una situación de pobreza extrema. Mientras el 70\% de los quechua hablantes se encuentra debajo de la línea de pobreza, esta situación afecta al $45 \%$ de la población hispanohablante. problema es que la pirámide que representa la regresiva distribución del ingreso no se ha alterado significativamente desde 1961, cuando empezaron las mediciones. Por el contrario, parece que se ha hecho mucho más aguda. Se estima que el $1 \%$ de la población está percibiendo $1 / 3$ del ingreso nacional mientras que el $10 \%$ recibe el $50 \%$ y el tercio más pobre sólo percibe el 5\% de la renta nacional. En 1995, por ejemplo, las consecuencias de esta distribución tan regresiva eran dramáticas. Un informe del Banco Mundial calculaba que el 10\% mejor dotado tenía 84 veces más recursos que el 10\% más pobre (en otros países la distancia era de 15 a 1 ).

En consonancia con estas cifras, un estudio

Las brechas ocupacionales que nos agobian también son notorias. De los cerca de 11.5 millones de personas que integran la población económicamente activa (PEA a partir de los 15 años) no más del $40 \%$

está adecuadamente empleada. Imaginemos cómo el otro $60 \%$, que enfrenta el desempleo (10\%) y el subempleo $(50 \%)$, está generando sus propias oportunidades económicas $\mathrm{y}$, concomitantemente, un sinnúmero de ordenamientos normativos, incluido el llamado "informal", sobre las formas de producción, circulación y distribución de los recursos que genera para atender sus necesidades. Por cierto que el problema del sub y desempleo está estructuralmente ligado a la cuestión de la distribución del ingreso.

En este ámbito, es lamentable decir que el Perú registra uno de los peores indices de desigualdad y pobreza en América Latina. El realizado por la consultora Apoyo en 1999 sobre los ingresos familiares en los niveles socio-económicos limeños graficó las tremendas disparidades que experimentamos. Basado en la nueva escala que incorpora un segmento más $(E)$ a la conocida clasificación cuatripartita (A, B, C y D), el estudio concluye que cerca de 800,000 limeños ( $11 \%$ del total) pertenecientes al segmento $E$ tienen un ingreso familiar de US\$ 147.00 al mes. En contraste, el segmento $\mathrm{A}$, conformado por unas 240,000 personas $(3.4 \%)$ tiene un ingreso mensual familiar de US $\$ 3,320.00$. Entre ambos extremos, los segmentos B, con 1'006,000 habitantes (14\%) y US\$ 874.00 de ingreso familiar mensual; $C$, con $2^{\prime} 360,000$ personas ( $34 \%$ ) y US $\$ 348.00$ de ingresos mensuales por familia; y el D, con $2^{\prime} 582,500(37 \%)$ y US\$ 229.00 de ingreso familiar mensual, integran los estamentos intermedios de la pirámide limeña. 
Ante estas cifras y el cuadro de desigualdad económica, heterogeneidad social y diversidad cultural que hemos esbozado, se hace realmente imposible pensar que el derecho moderno opera como una geometría normativa aplicable mecánica y uniformemente sobre toda la sociedad peruana. En principio, el derecho jamás se aplica en forma mecánica pues la interpretación de normas, principios $\mathrm{y}$ procedimientos es un elemento fundamental en la operación de cualquier sistema legal. Esa actividad interpretativa genera una diversidad de significados que contribuye a perfilar el fenómeno de la pluralidad, por lo menos en el ámbito intrasistémico. Al margen de su inconstitucionalidad, la hipertrofia del fuero militar durante el régimen de Fujimori es un ejemplo de este desarrollo. Su avocamiento a causas criminales comunes, más allá de los delitos de función (e.g., delitos de narcotráfico cometidos por militares) o el juzgamiento de civiles por casos de terrorismo agravado grafican esta tendencia.

Por su parte, la famosa Sala Penal Transitoria de la Corte Suprema de la República, presidida por el vocal provisional Alejandro Rodríguez Medrano durante el último período de Fujimori, se convirtió en un sub-sistema de administración de justicia dentro del propio poder judicial. Tenía la facultad de nombrar y designar a las Salas de la Corte Superior y a los jueces de primera instancia que juzgaban los delitos bajo su jurisdicción (e.g., delitos tributarios y aduaneros, corrupción de funcionarios, fraude en administración de sociedades, delitos contra la administración de justicia). Esta atribución la ejercía más allá de la ley orgánica del poder judical y del propio régimen de excepción creado por la comisión de reforma judicial con el fin de crear una pirámide jurisdiccional manipulable y adicta al régimen. Además, tuvo un margen de discrecionalidad excepcional para beneficiar a los partidarios del gobierno y perseguir a sus opositores con decisiones judiciales ciertamente cuestionables pero lamentablemente ejecutadas y eficaces. Bajo la lógica de la cleptocracia autoritaria instaurada por Fujimori, era esencial contar con los canales judiciales necesarios para encubrir los delitos cometidos, manipular la normatividad y las sanciones en función de los intereses del régimen, y acallar a los opositores aplicándoles "la ley" (e.g., casos de Baruch Ivcher, Genaro Delgado Parker y Jaime Mur-Delia Revoredo de Mur).

En general, un informe del Banco Mundial (Más allá del consenso de Washington. Las instituciones importan) identificó que uno de los principales problemas en la era fujimorista fue el desarrollo de un sistema de administración pública de facto que sobrepasaba al de jure, fomentando la informalización de la propia formalidad estatal y con ello la pluralidad interna. Más allá de la contingencia política, es necesario reconocer que esa pluralidad intrasistémica tiene un caracter estructural y se expresa, por ejemplo, en las diferentes concepciones y aplicaciones de las nociones de propiedad o contrato en las diversas ramas del derecho oficial (e.g., civil, agrario, laboral, administrativo). La multiplicación y diversificación de los significados produce la apertura y hasta el estallido del signo jurídico.

Por otro lado, resulta evidente que en el Perú no están dadas las condiciones sociales, económicas y culturales para que el derecho estatal opere según 
sus propios postulados. Cualquier sistema jurídico moderno puede tolerar sólo cierto grado de disparidades sociales, económicas y culturales. Más allá de ese umbral el sistema estalla, sea porque las personas involucradas no comparten un universo de significación mínimo, porque la asimétrica asignación de recursos impide la formación de una sociedad de ciudadanos dialogantes, o sea porque la dramática verticalidad social genera relaciones de poder intraducibles en el ámbito de los derechos y obligaciones propio de la concepción moderna. Eso es lo que ha ocurrido, precisamente, en el Perú. Si postulamos una definición del derecho como un sistema de asignación de derechos y obligaciones, es imprescindible crear o mantener un sustrato común no sólo material y económico sino también cultural y social para que el agregado humano suscriba el contrato social implícito en esa formulación política y legal. De lo contrario no lo suscribirá y se producirá, como en efecto se ha producido, la deslegitimación del sistema oficial.

Ante esta situación fluyen algunas preguntas sobre la vigencia efectiva y no sólo formal del derecho estatal. ¿Qué sucede cuando los presupuestos culturales no son compartidos por toda la población? ¿Qué ocurre cuando el derecho es etnocéntrico porque está fundado en postulados supuestamente universales y neutrales que pretenden hacer invisibles evidentes diferencias culturales? Es necesario enfatizar que esas categorías propias de la modernidad capitalista (e.g., ciudadano, consumidor, propiedad, contrato) pertenecen a una matriz cultural e histórica tan contingente y arbitraria como cualquier otra. Por eso su pretensión de trascendencia, neutralidad y universalidad carece de sustento empírico y más bien opera como una forma de legitimación política e ideológica. Si la población no comparte ese sustrato cultural, mal se puede pensar que el estado va a lograr imponer su hegemonía legal.

Además, cabe preguntarse, ¿qué sucede cuando lascondiciones sociales y económicas impiden el ejercicio de los derechos y obligaciones asignados? Cuando las disparidades son tan grandes, los "ciudadanos" no comparten, en la práctica, una plataforma común para accionar jurídicamente $\mathrm{y}$ acceder a las instituciones oficiales en pie de igualdad. Por eso, la inequitativa distribución de los recursos materiales y simbólicos necesarios para operar en el mundo jurídico oficial (an/alfabetismo, educación cívica básica, acceso a la administración de justicia, asesoria legal adecuada) impide la vigencia universal del derecho oficial y genera su ilegitimidad social.

\section{III.- El vértigo del estado}

¿Cuál es la respuesta estatal frente a esta problemática? Como indicamos líneas arriba, no puede ser más grandilocuente y errada al sostener que el derecho "moderno" es la única, incuestionable y categórica solución. En lugar de entrar en diálogo con la sociedad para enfrentar la diversidad cultural y la complejidad social, el estado se empecina en acelerar su producción legislativa, conduciéndonos a la hipertrofia legal. En lugar de enfrentar la cuestión de cómo elaborar un sistema legal que acoja y potencie la diversidad con el fin de evitar, precisamente, la anomia social y la sobreproducción normativa, el estado ha respondido ensanchando las brechas que lo distancian de la sociedad y mojando su propio papel. 
Algunos indicadores nos permiten sustentar esta afirmación. El primero es que al decir de Mario Vargas Llosa en su prólogo a El Otro Sendero (1986) de Hernando de Soto, la "telaraña legal" que asfixiaba a la sociedad peruana en ese momento estaba tejida por más de medio millón de leyes, decretos leyes, decretos supremos, resoluciones, reglamentos y ordenanzas vigentes. El aparente origen alucinatorio de este aserto se desmiente cuando tomamos en cuenta la increíble "productividad" jurídica oficial. Sólo como referente anecdótico pero revelador recuérdese la promulgación y derogación inmediata del reglamento sobre la inversión de fondos de las AFPs en el extranjero o la del decreto que pretendía normar cómo los padres debían nombrar a sus hijos o las recientes marchas y contramarchas sobre la suspensión de las retenciones en las rentas de cuarta categoría.

De Soto indica que entre 1947 y 1985 el Poder Ejecutivo produjo un promedio de 27,000 normas y decisiones administrativas por año frente al Poder Legislativo que sólo emitió el $1 \%$ de las normas del período. Mientras el número de leyes numeradas desde 1904 a la fecha bordea las 27,200, la contribución del "gobierno revolucionario de las Fuerzas Armadas" (1968-1980) a la telaraña legal fue considerable. En ambas "fases", las dictaduras de Velasco Alvarado y Morales-Bermúdez emitieron alrededor de 6,200 decretos leyes y 335,550 normas y decisiones administrativas. Aunque suene paradójico, los gobiernos dictatoriales siempre han sido pródigos en la producción de derecho.

En cualquier caso, el desenfreno también se expresa en términos del objeto normado. La notable recopilación de Francisco Ballón (1991) sobre el derecho oficial frente a la Amazonia revela que desde 1822 hasta 1989 el estado dictó 18,349 normas (leyes, decretos, resoluciones) específicamente dirigidas a regular paisajes humanos y geográficos por demás inasibles para el centralismo limeño ( $\sin$ contar los dispositivos generales aplicables). El efecto ha sido la formación de una maraña legislativa inspirada en un reservorio simbólico repleto de imágenes sobre el "salvajismo", la civilización, el progreso y la prosperidad pero ajena a las sociedades amazónicas.

Parte de esta maraña se genera en la inconsistencia legislativa. El caso de la ley de reforma agraria de 1969, estudiado por Luis Pásara (1978), resulta típico. Durante los primeros 14 meses de su vigencia se promulgaron otros 18 decretos leyes modificatorios, ampliatorios o complementarios. Esta anomalía ha terminado siendo un patrón en la actividad oficial, al punto de haberse acuñado el célebre acrónimo TUO para referirse a los "textos únicos ordenados" que pretenden sistematizar los balbuceantes rompecabezas promulgados por los gobiernos. Por cierto que la vorágine legalista continúa. Sólo a modo de ejemplo podemos indicar que el archivo informático del estudio de abogados más importante de Lima registra más de 27,250 dispositivos producidos por la pirámide estatal entre 1990 y 1999 (desde leyes hasta resoluciones directorales y subjefaturales). Y eso que este archivo sólo recoge aquéllos relevantes a las áreas de su especialidad. Por cierto que el crecido número de normas promulgadas y vigentes no es, en sí mismo, el meollo de la cuestión. La febril imaginación jurídica bien podría diseñar una pirámide normativa perfectamente 
lógica y sistemática. El problema central es la incoherencia de las políticas públicas plasmadas legalmente y el cúmulo de proposiciones contradictorias planteadas al interior del propio edificio jurídico oficial.

Además, cual metástasis que fatiga aún más al cuerpo social, la profesión legal incrementa sus filas incansablemente. El Colegio de Abogados de Lima estima que 31,000 de los 45,000 abogados peruanos radican en Lima y 22,000 ejercen activamente la profesión. Adicionalmente, el Colegio de Abogados del Callao registra 4,000 inscritos, el de Arequipa 3,000, el de La Libertad 2,400 y el de Puno 1,100. El año pasado, un informe periodístico señalaba que, hacia 1996, Abancay tenía 100 abogados para 120 presos (El Comercio A2, 126-00). El problema también se grafica en el ámbito de la educacion legal. En 1998, por ejemplo, las universidades titularon un abogado cada tres horas $y$ media, y 37,000 estudiantes seguían la carrera de Derecho en 42 facultades del país. De éstas, 10 funcionan en Lima, 4 en La Libertad, 3 en Lambayeque, 3 en Ancash y 2 en Loreto.

Cualquiera que conozca estas ciudades sabrá que la oferta de servicios profesionales ha sufrido un incremento desmesurado a la par que la calidad de los servicios profersionales se ha deteriorado tremendamente. Peor aún, la masificación de la enseñanza legal exacerba la limitada preparación académica y profesional de los estudiantes y les garantiza un futuro de sub y desempleo. Si a este contingente le añadimos los miles de tinterillos y practicantes informales que también prestan servicios legales, la imagen del avispero es la única que puede ayudarnos a comprender el tipo de actividad legal que se realiza en el Perú.

La vorágine legal que padecemos como fruto de las erradas políticas estatales frente a la sociedad también tiene un correlato en el ámbito constitucional y, dicho sea de paso, responde a la tradición jurídica latinoamericana. La inestabilidad política y legal de nuestros paises se expresa, por ejemplo, en la acelerada producción de cartas magnas. En los casi dos siglos que tenemos de vida republicana, nuestras 20 repúblicas han promulgado unas 220 constituciones, lo cual equivale a un promedio de 11 por país e indican que cada una rigió 17 años aproximadamente.

Por su parte el Perú, entre 1821 y 2001, promulgó 14 cartas fundamentales. Esta cuenta incluye el Estatuto Provisorio de San Martín (1821) y excluye tanto las constituciones de los estados nor $\mathrm{y}$ sud peruanos de la confederación PeruanoBoliviana (1836) como el Estatuto Provisorio de Piérola (1879). Así, los textos de 1821, 1823, 1826, 1828, 1834, 1837 (Ley Fundamental de la Confederación Perú-Boliviana), 1839, 1856, 1860, 1867, 1920, 1933, 1979 y 1993 ilustran nuestra copiosa producción constitucional. También significan que en 180 años de vida republicana hemos tenido una nueva carta cada 13 años, en promedio, y nada permite pensar que esta tendencia histórica sea revertida. Por el contrario, existen iniciativas destinadas a cambiar la actual constitución. 
En términos del estado de derecho y la democracia, la inestabilidad también es flagrante. La constitución de 1933, vigente formalmente casi medio siglo, sólo rigió 8 años en forma plena, presidiendo 2 períodos democráticoconstitucionales (1945-1948, 1963-1968). El resto del tiempo el sino dictatorial o los regímenes democráticos de "baja intensidad" rigieron los destinos del país (e.g., segundo gobierno de Prado o segunda parte del gobierno de Odría). La de 1979, ideada como la constitución del siglo XXI, sólo rigió 13 años y la de 1993 ha estado permanentemente bajo estado de emergencia debido a las flagrantes medidas anticonstitucionales de sus propios gestores y a la lucha contra el terrorismo (e.g., a inicios de 1999, 35 provincias con más de 4.5 millones de habitantes se encontraban bajo estado de emergencia y en la mayoría seguían operando los comandos político-militares).

La crítica situación del derecho oficial también se expresa en el ámbito judicial, sometido una vez más al ritual de la reforma aparente $\mathrm{y}$ manipulatoria durante el gobierno anterior. Es sintomático, por ejemplo, que en 1998 la Defensoría del Pueblo haya detectado que el propio estado se negaba a cumplir el $65 \%$ de las sentencias dictadas en su contra por el Poder Judicial (invocando razones presupuestales). Si el mismisimo estado desobedece sus dictados y erosiona la credibilidad de sus instituciones, podemos imaginar cuál es la legitimidad que éstas tienen frente a la sociedad global. Medidas como la desjudicialización de algunos procedimientos no-contenciosos o la conciliación como vía alternativa de solución de conflictos son respuestas oficiales (tímidas) que sólo confirman el descrédito del poder judicial y fomentan la pluralidad intrasistémica.

\section{IV.- Más allá del estado}

¿Qué hacer frente a este panorama? Más allá de los grandes procesos políticos y económicos que contribuirán a cerrar las brechas señaladas -desarrollo, descentralización, redistribución, regionalización, democratización, inversión social- es imprescindible plantear algunas cuestiones fundamentales sobre el papel del derecho y del estado en la regulación social y sobre las tareas de la antropología legal peruana. En cuanto al primer punto, es necesario preguntarse si el estado debe seguir apostando por afirmar su hegemonía legal a toda costa. Debe o no mantener su acelerada producción jurídica o debe, más bien, forjar una nueva relación con la sociedad basada en el reconocimiento de la diversidad social y normativa. Magnificar aún más la hipertrofia legal es apostar por la política del avestruz y avivar el espejismo de creer que más producción normativa produce mayor control social.

Por el contrario, en lugar de promover el cumplimiento de la ley estatal, la maraña legislativa induce a la llamada informalidad, a la resistencia (activa o pasiva) y a la emergencia de espacios sociales semi-autónomos que crean sus propios mecanismos de regulación, coacción y sanción. Por eso el objetivo es fomentar el diálogo entre el estado y la sociedad civil. Así, los legisladores y gobernantes abandonarán la torre de papel que han creado y reconocerán que la pluralidad no es sólo un problema que debe solucionarse a través de la homogenización forzada sino una gran oportunidad para replantear los fundamentos mismos del estado nacional y del estado de derecho. 
La alternaiva radica en aplicar la misma lógica propuesta para liberar a la economía del intervencionismo estatal, permitiendo que las fuerzas y grupos sociales afirmen su iniciativa normativa y potencien sus mecanismos de autocomposición (en lugar de estar sujetos a la heterocomposición estatal). De manera semejante a la libertad económica, la autonomía normativa también debe estar sujeta a un contrato social implícito y a una ética fundamental que evite la anarquía o los desequilibrios de poder conducentes a la destrucción del propio tejido social. Naturalmente que la devolución de la potestad normativa y jurisdiccional a las organizaciones sociales consuetudinarias no pretende desarticular (aún más) al país o crear el caos social sino recrear las relaciones del estado con la sociedad bajo premisas diferentes a las que inspiraron la formación del estado-nación moderno. En lugar de centralizar esas potestades normativas y jurisdiccionales en órganos estatales especializados el objetivo es desestatizarlas, reconociendo y potenciando su vigencia y efectividad social. Para ello es necesario ensanchar las avenidas legislativas, administrativas y jurisprudenciales del estado, propiciar una respuesta tolerante a la diversidad social y normativa y fomentar el diálogo entre todos los agentes sociales involucrados.

Se trata, entonces, de sustentar la legislación, la jurisprudencia y las políticas públicas en el estudio de la realidad socio-legal misma y no en espejismos inconducentes o en el plagio de instituciones y modelos ajenos (e.g., los paquetes de reformas administrativas y judiciales que la banca multilateral diseña e impone como parte de sus "condicionalidades"). Así como en la actualidad se exige que los proyectos de ley de los congresistas contengan un análisis costo-beneficio para estimar el impacto que tendrían sobre la economía, de igual manera se debería exigir que cualquier norma o decisión administrativa que afecte a las organizaciones sociales consuetudinarias se base en un estudio de las realidades que se pretenden regular (cf. Sagasti, Iguíñiz, Schuldt 1999, 55). Se trata, en suma, de reemplazar el enfoque instrumentalista que inspira a los gobernantes nacionales, en donde la realidad social funciona a imagen y semejanza de la ley, por un enfoque centrado en el significado social del derecho y en cómo éste opera empíricamente, más allá de los buenos deseos de los promulgadores.

Ello frenará la vorágine legislativa $y$, concurrentemente, abrirá el espacio político y legal para que las creaciones normativas consuetudinarias afirmen su vigencia social. Aquí nos toparemos con la consabida atingencia sobre las posibles amenazas a la universalidad de los derechos humanos pero, en todo caso, éstas deben ser resueltas en forma casuística y, al hacerlo, se descubrirá que la gran mayoría de las prácticas sociales no colisionan con los derechos fundamentales. En los casos de colisión será necesario, además de cuestionar las interpretaciones etnocéntricas del régimen de protección de los derechos humanos, avanzar hacia una posición que logre armonizar y respetar el ejercicio de los derechos colectivos e individuales de las personas. Esta posición deberá alcanzarse a partir del diálogo con las organizaciones sociales consuetudinarias, desterrando su papel histórico de "receptoras" de directrices y reemplazándolo por el de "emisoras" capaces de entablar una nueva 
relación con el estado y el resto de la sociedad peruana (ver Urteaga 1993).

La segunda cuestión fundamental remite al conocimiento antropológico o sociológico que tenemos sobre las diferentes formas de regulación social en el Perú. La antropología legal peruana no ha sido capaz de elaborar un mapa etnográfico certero y confiable de nuestra realidad jurídica porque la mayoría de sus contribuciones se inspira en marcos teóricos que distorsionan la realidad etnográfica (ver introducción). Por eso resulta imprescindible manejar adecuadamente los marcos teóricos y metodológicos de la antropología legal contemporánea y aproximarse de nuevo a la compleja realidad sociolegal peruana. No se trata de importar, una vez más, modelos teóricos para aplicarlos mecánicamente. Se trata de evaluar su utilidad y emplearlos reflexivamente. Sólo asi la antropología legal alcanzará su potencial académico y político.

En oposición a las ideas políticas que fundaron al Perú como un estado-nación moderno en el siglo XIX, la historia se ha encargado de cuestionar ese proyecto liberal homogenizante. Por eso, en el campo del derecho, la tarea de afirmar la hegemonía estatal sobre el territorio nacional con el fin de establecer su monopolio jurídico sobre todos los aspectos de la vida social contrasta con la gran diversidad de espacios sociales y normativos desarrollados más allá del designio oficial. Por eso estamos inmersos en una situación de pluralidad legal, donde múltiples legalidades operan y rigen simultáneamente. El reto está en construir un nuevo "contrato social" verdaderamente inclusivo, que se alimente de la pluralidad y que, a contracorriente del designio moderno, se nutra de la diversidad con el fin de articularla. No se trata df: negarla. Se trata más bien de afirmarla en todo su esplendor.
Nota.- Los lectores interesados en conocer las teorías sobre el pluralismo jurídico pueden revisar, como texto introductorio, el de Guevara Gil y Thome (1992) que aparece traducido en el número 19 de Ius et Veritas (Lima, 1999). Para aproximarse a los aportes posteriores se sugiere examinar los trabajos de Benda-Beckmann y Hoekema (1997), Petersen y Zahle (especialmente el artículo de John Griffiths; 1995), y Santos (1995, una sección traducida en 1998). También resulta aconsejable ver las revistas especializadas PoLAR (Political and Legal Anthropology Review), editada por la sección especializada de la American Anthropological Association, y el Journal of Legal Pluralism publicado por la Commission on Folk Law and Legal Pluralism (Holanda). Por último, conviene leer el Canadian Journal of Law and Society (1997) que dedica un número monográfico a la cuestión del pluralismo legal (ver, en especial, artículos de Belley; Kleinhans y Macdonald; y Duncanson). D\&S

\section{BIBLIOGRAFIA}

Ballón, Francisco 1991 La Amazonía en la Norma Oficial Peruana: 1821-1990. 4 tomos. Lima: Centro de Investigación y Promoción Amazónica.

Benda-Beckmann. Franz y Keebet von y André Hoekema (eds). 1997 Natural Resources, Environment, and Legal Pluralism. Número especial de Law \& Amthropology 9. La Haya: Kluwer International.

Bonilla, Heraclio. 1988 "Constitutionalism in Latin American History and Today". Working paper, American Council of Learned Societies, New York. 
Canadian Journal of Law and Society. 1997 Le Pluralisme Juridique/Legal Pluralism 12(2). Número especial editado por Jean-Guy Belley.

Figueroa, Adolfo, T. Altamirano y D. Sulmont. 1996 Exclusión Social y Desigualdad en el Perú. Lima: Organización Internacional del Trabajo.

Guevara Gil, Armando y Joseph Thome. 1992/1999 "Notes on Legal Pluralism". Beyond Law, ILSA 2(5):75-102. Traducido en Ius et Veritas 19, 1999:286-304, Lima.

Guevara Gil, Armando. 1998 "La Antropología del Derecho en el Perú: Una Disciplina Marginal y Periférica". América Indígena, editoras especiales Milka Castro Lucic y María Teresa Sierra, LVIII(1-2):341-373.

Iguíniz, Javier. 1998 "Informalidad y Ley en el Gobierno Peruano". Quehacer, DESCO, 114:53-57.

Instituto Cuánto y UNICEF. 1996 Retrato de la Familia Peruana. Niveles de Vida, 1994 (segunda parte). Lima: Editorial Navarrete.

López, Sinesio. 1997 Ciudadanos Reales e Imaginarios. Concepciones, Desarrollo y Mapas de la Ciudadanía en el Perú. Lima: Instituto de Diálogo y Propuestas.

MacLean, Roberto. 1998 "La eficiencia social de las leyes como elemento del desarrollo político y económico". Ius et Veritas 17:8-19.
Pásaa, Luis. 1978 Reforma Agraria: Derecho y Conflicto. Lima: Instituto de Estudios Peruanos.

Petersen, Hanne y Henrik Zahle. 1995 Legal Polycentricity: Consequences of Pluralism in Law. Aldershot: Dartmouth.

Revilla, Ana Teresa y Jorge Price. 1992 La Administración de la Justicia Informal. Posibilidades de Integración. Lima: Fundación M.J. Bustamante de la Fuente.

Sagasti, Francisco, Javier Iguíñiz y Jürgen Schuldt. 1999 Equidad, Integración Social y Desarrollo: Hacia un Nuevo Enfoque para la Política Social en América Latina. Lima: AGENDA: Perú, Centro de Investigación de la Universidad del Pacífico.

Santos, Boaventura de Sousa. 1995 Toward a New Common Sense. Law, Science and Politics in the Paradigmatic Transition. Nueva York: Routledge.

Santos, Boaventura de Sousa. 1998 La Globalización del Derecho. Los Nuevos Caminos de la Regulación y la Emancipación. Bogotá: Universidad Nacional de Colombia-ILSA.

Soto, Hernando de. 1986 El Otro Sendero. Lima: Instituto Libertad y Democracia.

Trazegnies, Fernando de. 1977 "El caso Huayanay: El Derecho en situación límite." Cuadernos Agrarios 1:73-118.

Trazegnies, Fernando de. 1993 Postmodernidad 
y Pluralismo Jurídico. Arequipa: Universidad Nacional de San Agustín.

Urteaga, Patricia. 1993 "Comentarios". Comunidades Campesinas y Nativas en el-Nuevo Contexto Nacional, Fernando de Trazegnies et al., pp. 47-50. Lima: CAAAP-SER
Vásquez, Enrique (ed.). 2000 Impacto de la Inversión Social en el Perú. Lima: Centro de Investigaciones de la Universidad del Pacífico, International Development Research Centre 